\title{
A Smart Billing System for Enhancement of Renewable Energy to Non- Electrified Communities in Nigeria
}

\author{
Olufemi Abraham \\ Graduate School of Technology Kobe Institute of Computing \\ 403 Grace Heights, 6-7-5 Motoyama-Minamimachi, Higashinada, Kobe. 658-0015 Japan \\ s18132@al.kic.ac.jp; olufemiabraham@gmail.com
}

\section{Extended Abstract}

There is high level of transmission and distribution power losses in energy sector of Nigeria, thereby leading to shortage of electricity power supply to domestic, industrial and commercial consumers [1]. In other to meet up with daily energy consumption requirements, consumers generally resolve to usage of fossil fuel generators, which is very expensive and not sustainable because of high cost of procurement and maintenance. In addition to this, consumers were expected to pay monthly bills to distribution companies for irregular and erratic power supplied for those connected to the national grid even though more than $50 \%$ of the entire population were without electricity meters [2]. Although the concept of prepaid meter is deployed by the DisCOs (distribution company), the few residences with this meter still receive bills estimation as this meter are frequently bypass by consumers (energy theft). The metering and billing are manually controlled. This has led to inaccuracy, high operational cost and unnecessary delays.

The analysis of this study was based on the high percentage of mobile phone subscribers (about 90\%) [3], feedback mechanism and results received from the members of the public via questionnaires. The obtained results enabled this study to get to the far-reaching recommendations which are ideal for the successful implementation of the Smart Metering System (SMS). The content is an IoT based electricity energy meter using NodeMCU whose functionality is to link the meter with mobile device wirelessly with consumers, to know the periodic energy consumed and to distribution company through LoRaWAN [4]

The study has revealed an IoT cloud-based billing system scores highly as a key option to be considered for alleviation of the above problems. Findings indicate that given the currently available cloud computing technology with a lot of wireless connected devices, the new system shall go a long way not only in solving metering and accurate billing but also can maintain and improve system security in the face of challenges such as ageing infrastructure, rising demand, variable generation and electric vehicle deployment, by using sensor technology across the electricity system[5].

The objective of this research is to close the gap between the current situation and the ideal situation of regular power and accurate billing. That consumers can pay according to power usage using prepayment electricity metering system.

This paper explores the design, implementation and application of SBS for electricity consumers in Nigeria. For low electricity consumption (domestic consumers), a smart prepaid meter has been designed which needs a prepaid card to keep the electricity supply continue. With SBS, this system can easily be enhanced to boast regular supply of electricity by encouraging investors in generation of renewable power plants (UNDP SDGs [6] standard such as Solar, Wind, Hydro) to complement the existing plants hence enhancing more regular power supply.

The impact of this is that people can use electricity, pay as consumed and can also monitor and manage energy usage over a period of time as oppose to the current situation where bills are distributed indiscriminately to consumers. This solution eliminates estimated billing and bring about transparency to both the Distribution companies and the consumers.

Keywords: Pre-Paid, Post-Paid and estimated electricity billing system, electricity consumption, Subscriber satisfaction, Smart Billing System (SBS), Renewable Power Plants. Sustainable Development Goals (SDGs), Micro Controller Unit (MCU), Distribution Company (DisCO), Low Power, Wide Area (LPWA) networking protocol (LoRaWAN)

\section{References}

[1] A. Hamilton (2020, Oct 23). Article on Federal Republic of Nigeria ( $2^{\text {nd }}$ ed)

[Online]. Available: https://www.britannica.com/place/Nigeria 
[2] G. Ibenegbu (2018, May 21). Legit reporting poor power supply in Nigeria ( $1^{\text {st }}$ ed.)

[Online]. Available: https://www.legit.ng/1170127-poor-power-supply-nigeria-reason.html\#1170127

[3] O. Kolawole (2019, May 25) Jumia Reporting Key Nigerian Facts ( $1^{\text {st }}$ ed)

[Online]. Available: https://www.jumia.com.ng/sp-mobile-report/

[4] R. Jain (2018, July 10). CircuitDigest-IoT Based Electricity Energy Meter Using ESP12 and Arduino (3rd ed.)

[Online]. Available: https://circuitdigest.com/microcontroller-projects/iot-electricity-energy-meter-using-esp12-arduino

[5] M. Naik and al (2019, Jan 5). International Journal of Engineering Research and Technology (IJERT) (1 ${ }^{\text {st }}$ ed)

[Online].Available:https://www.ijert.org/implementation-of-iot-based-electricity-controlled-prepaid-energy-metermonitoring-and-bill-payment-system

[6] UNDP - United Nation Sustainable Development Goal -7

[Online]. Available: https://www.undp.org/content/undp/en/home/sustainable-development-goals/goal-7-affordable-andclean-energy.html 